\title{
The small cerebellum in children - a useful approach on MRI
}

\author{
S Richards, $M B$ ChB \\ $S$ Adronikou, $M B B C h$, \\ FCR Diag (SA), FRCR (Lond), PhD \\ Department of Paediatric Radiology, Tygerberg Hospital and University of \\ Stellenbosch
}

Several conditions may present with a small cerebellum on MRI. These can be classified into 3 categories.

An atrophic cerebellum is a small cerebellum with enlarged fissures. A cerebellum is also considered to be atrophic if it has been shown to have undergone progressive loss of volume (Fig. 1). ${ }^{1}$ This can occur with children in the hereditary condition of Friedrich's or spinocerebellar ataxia.

A hypoplastic cerebellum has folia which are in proportion to the fissures: a uniformly small perfectly proportioned structure (Fig. 2). Examples of cerebellar hypoplasia include pontocerebellar hypoplasia and Wolfram syndrome. ${ }^{1}$

Lastly, a hypogenetic cerebellum has a formed superior portion, but an absent inferior portion (Figs 3 and 4). In the Dandy Walker complex a focal insult to the developing cerebellum causes variable hypoplasia of the postero-inferior portion of the cerebellar vermis and dysgenesis

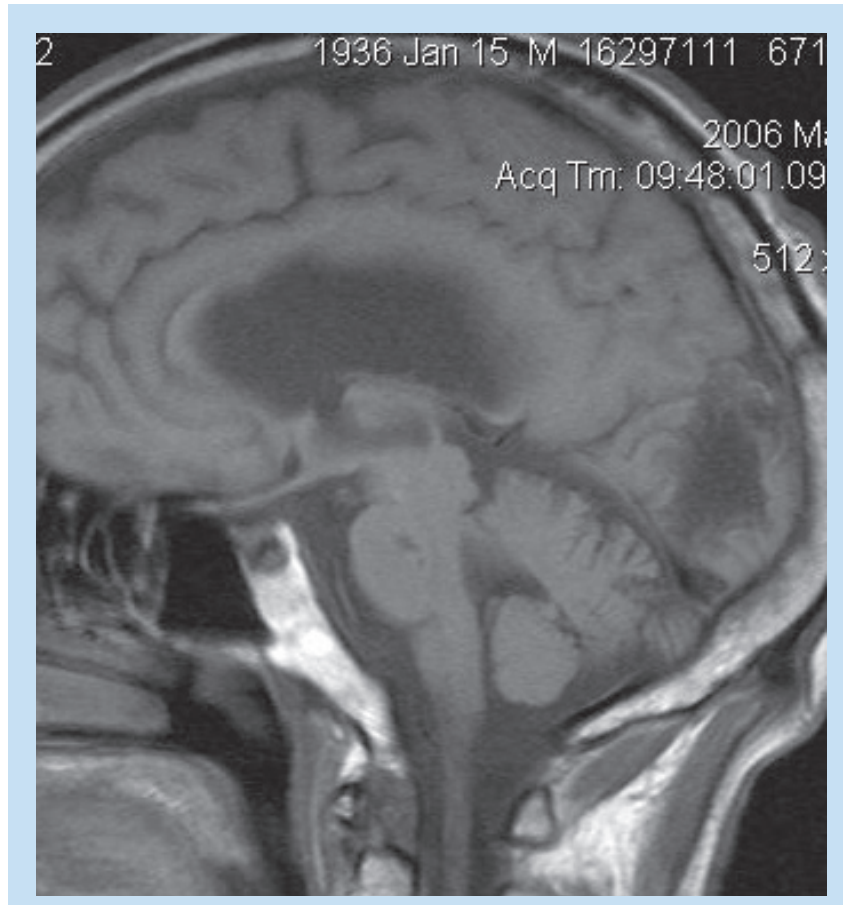

Fig. 1. Cerebellar atrophy. Sagittal T1 image shows deepened cerebellar fissures relative to folial size.

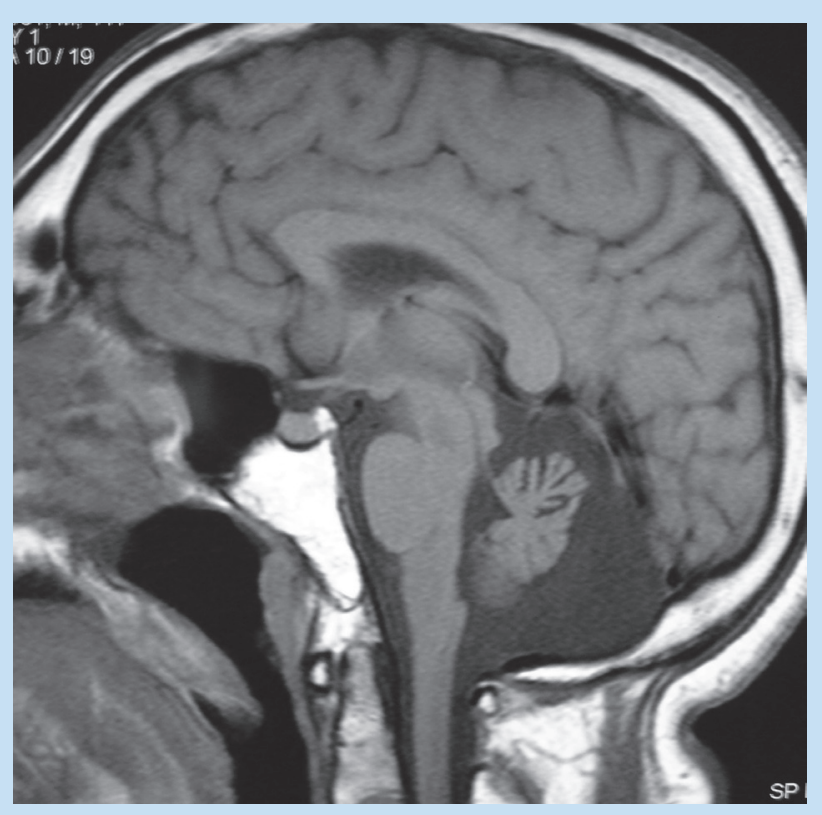

Fig. 2. Cerebellar hypoplasia. Sagittal T1 image shows the folia and fissures to be in proportion in a small cerebellum.

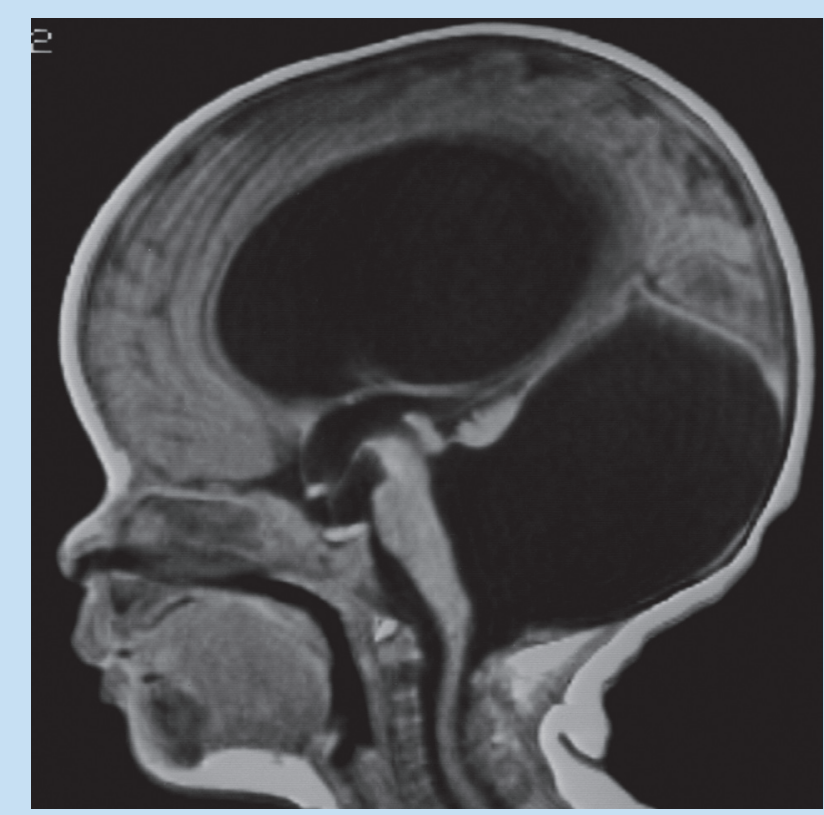

Fig. 3. Cerebellar hypogenesis. Sagittal T1 image shows almost complete absence of the vermis and an enlarged posterior fossa with associated hydrocephalus. 


\section{CASE REPORT}

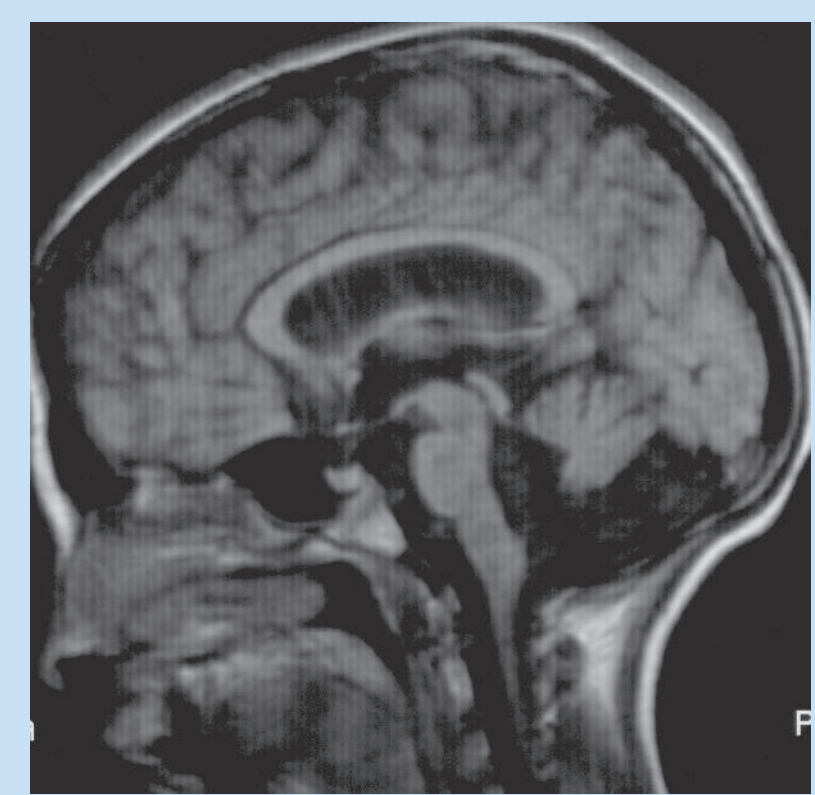

Fig. 4. Cerebellar hypogenesis. Sagittal T1 image with cerebellum demonstrating dysgenesis with a formed superior and absent inferior portion. of the hemispheres. There is communication between the 4 th ventricle and cisterna magna, and cystic dilatation of the 4 th ventricle in the true Dandy Walker syndrome. ${ }^{2}$ The Dandy Walker complex is a spectrum of posterior fossa cystic anomalies. ${ }^{1}$

1. Barkovich JA. Paediatric Neuroimaging, 3rd ed. Philadelphia: Lippincott Williams \& Wilkins, 2000: 143145, 339-341.

2. Dahnert W. Radiology Review Manual, 5th ed. Philadelphia: Lippincott, Williams \& Wilkins, 2003: 274

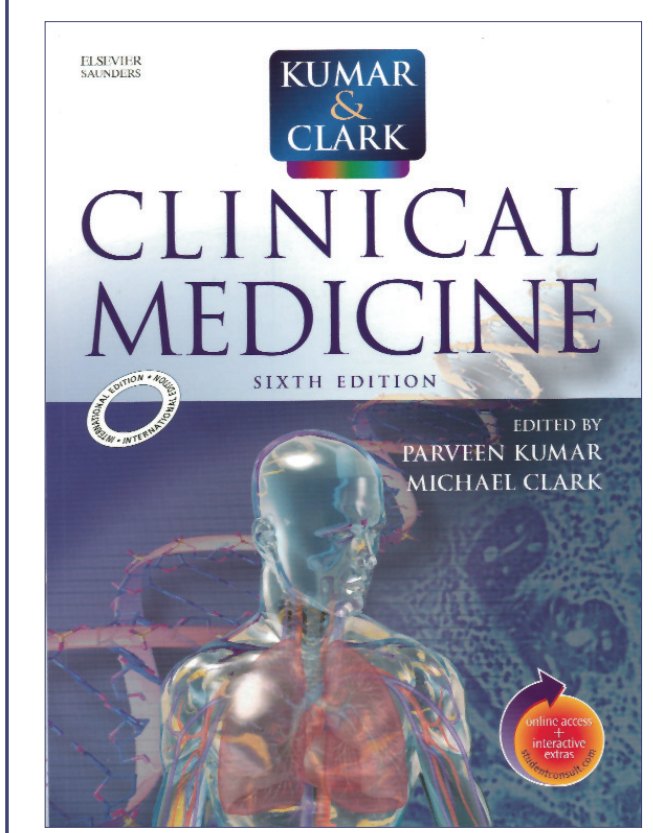

\section{PRICE: R380.00 SAMA MEMBERS: R360.00}

TO ORDER CONTACT:

South African Medical Association Health \& Medical Publishing Group 1-2 Lonsdale Building, Gardener Way, Pinelands, 7405 Tel: (021) 530-6520/27 • Fax: (021) 531-4126

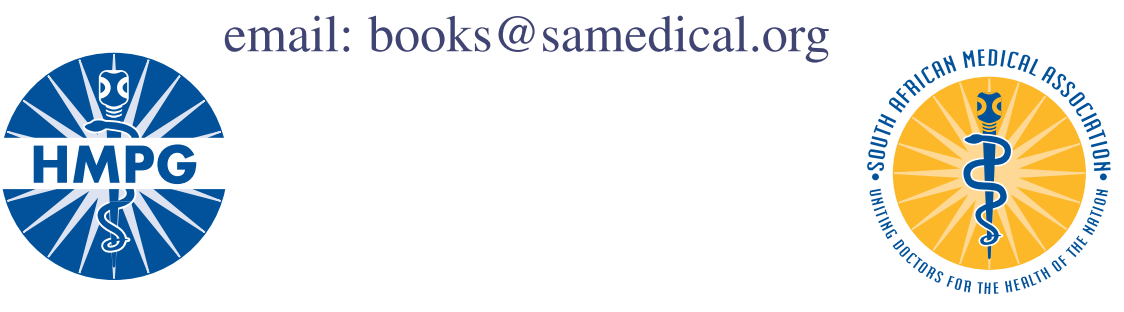

